\title{
DEREK BAIN
}

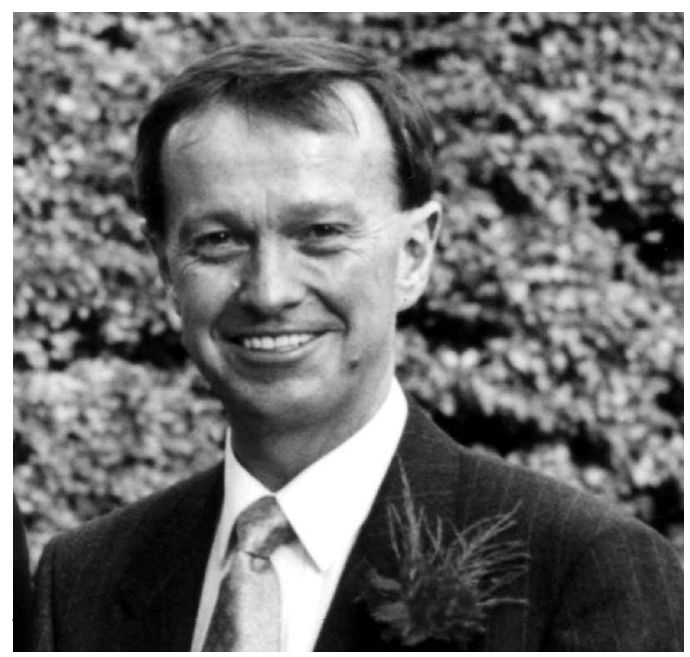

Perhaps the most demanding job in any scientific society is that of the Editor. He or she has the dual responsibility for maintaining a rigorous peer review process and for communicating new and exciting ideas to the scientific community (including the various funding bodies). Ultimately, successful science and scientists depend on good editing. It's a job that requires close attention to detail, a wide knowledge of the subject and a who's-who memory of the players in the field. In return for doing the job well there is little glory, the occasional free lunch or conference ticket, and the knowledge that editors make few friends among the authors that they help.

As Principal Editor of Clay Minerals for 13 years, Derek Bain is one of the unsung heroes of our Society, so it was a great pleasure to be able to sing his praises and present him with a gift from the Clay Minerals Group on the occasion of the Mineralogical Society's $125^{\text {th }}$ Anniversary Celebration in the Earth Galleries of the Natural History Museum, London.

During his term as Principal Editor, from January 1988 to March 2001, Derek oversaw the publication of $\sim 640$ papers in 55 issues, occupying 8440 pages of Clay Minerals. In that time, he and his Associate Editors handled about 970 manuscripts, and made Clay Minerals the Journal of the European Clay Groups, increasing the number of countries represented, from seven in 1988 , to 13 at the end of 2000 .

In the academic community, the use of impact factors has become all-important, as a measure of quality of the papers published in our journals. Throughout his tenure, Derek has ensured the continuation of Clay Minerals as a journal of the highest quality in its field. It is apposite that he should leave the job of Principal Editor on a high note: Clay Minerals went on-line last year and the last three volumes are now available.

Derek has been appointed the Editor-in-Chief of Clays and Clay Minerals from $1^{\text {st }}$ January 2001. On behalf of the Society I thank him for his unstinting service to clay mineralogy, and wish him well as Editor-in-Chief.

Dick Merriman

Chairman, Clay Minerals Group 1st March 2001 